\title{
The Application of Materials Balancing to the Characterization of Sequential Secondary Metabolite Formation in Streptomyces cattleya NRRL 8057
}

\author{
By MICHAEL E. BUSHELL* AND ALAN FRYDAY \\ Department of Microbiology, University of Surrey, Guildford, Surrey GU2 5XH, U.K.
}

(Received 6 October 1982; revised 15 December 1982)

\begin{abstract}
The high substrate yield factor $\left(0.73 \mathrm{~g}\right.$ biomass $\mathrm{g}$ glucose $\left.\mathrm{C}^{-1}\right)$ and low R.Q. (respiratory quotient, i.e. mol $\mathrm{CO}_{2}$ evolved per mol $\mathrm{O}_{2}$ consumed) value (0.8) measured during growth-phase batch cultures of Streptomyces cattleya could be rationalized in terms of the fermentation mass balance when the oxidized elemental composition of biomass was considered. R.Q. was also indicative of the sequence of secondary metabolite formation, the value rising in steps as each new product was formed. The period of maximum respiratory activity and phosphate uptake preceded maximum growth and glucose uptake. At the end of the lytic phase, a cyclopentenedione cobalt chelator was produced. The termination of lysis coincided with melanin production. Sequential cephamycin $\mathrm{C}$ and thienamycin production then took place. Specific hyphal protein content (per unit RNA) peaked before the production of each new metabolite. Melanin, cephamycin C and thienamycin production were initiated when glucose, ammonia and phosphate, respectively, became growth-limiting.
\end{abstract}

\section{INTRODUCTION}

Many secondary metabolite-producing microbial species synthesize a multiplicity of products rather than single compounds. In some cases, particularly amongst the Actinomycetales, chemically distinct metabolites are produced by a single strain (Hopwood, 1981). In a survey of antibiotic-producing actinomycetes (Umezawa, 1967), $11 \%$ of the species listed produced more than two different structures or classes of compounds. Hopwood's assertion that antibiotic discovery is a reflection of the intensity with which an organism is investigated (Hopwood, 1981) is supported by our own findings (e.g. Napier et al., 1977). Thus, with the widespread introduction of more sensitive screening procedures in recent years (Bushell, 1982) a more up to date survey would probably increase that proportion. Streptomyces cattleya NRRL 8057 produces cephamycin $\mathrm{C}$, penicillin $\mathrm{N}$, thienamycin, $N$-acetylthienamycin (Kahan et al., 1979) and a cyclopentenedione antibiotic (Noble et al., 1978) as secondary metabolites. Kitano et al. (1975) have suggested that thienamycin, the olivanic acids and clavulanic acid are cosynthesized with penicillins and/or cephalosporins. Multiproduct fermentations are, therefore, not uncommon in beta-lactam biosynthesis.

The concept of extracellular nutrient effectors for the regulation of secondary metabolism has provided a framework for commercial process optimization. Carbon catabolite, nitrogen metabolite and phosphate regulation have all been observed in antibiotic biosynthesis (Martin \& Demain, 1980) and a comparative study of this phenomenon has been made with cephalosporin production in Streptomyces clavuligerus (Aharonowitz \& Demain, 1977, 1978, 1979).

The use of the technique of materials balancing in fermentations has been applied to the estimation of biomass and primary metabolites (Cooney et al., 1977) employing on-line measurements of gaseous exchange and nitrogen demand. The procedure has been refined to provide continuous information on the energetic efficiency of biomass and product formation 
(Erickson et al., 1979) and rationalized with respect to substrates and products with different degrees of reduction (Roels, 1980). In this study we apply the technique to the characterization of a fermentation in which a number of secondary metabolites are formed, apparently in response to extracellular nutrient effectors.

\section{METHODS}

Organism and culture conditions. Streptomyces cattleya NRRL 8057 was grown in liquid culture under production conditions (see below) and single spore isolates from the culture tested for antibiotic production. One isolate (AB3) was selected and used throughout this study. Stocks were maintained as frozen spore suspensions as described previously (Bushell \& Nisbet, 1981). Fermenter cultivation was carried out in a one litre magnetically stirred vessel (model 500 series II, LH Fermentation, Stoke Poges, Bucks.) with the baffles removed. The working volume, temperature and agitation were $900 \mathrm{ml}, 28^{\circ} \mathrm{C}$ and 1000 r.p.m., respectively. Aeration was controlled manually at $29 \mathrm{ml} \mathrm{min}^{-1}$ using a high accuracy rotameter (model RS1, Glass Precision Engineering, Hemel Hempstead, Herts.). This low flow-rate was chosen in order to increase the sensitivity of gas analysis. In situ measurements of dissolved oxygen tensions with a Mackereth electrode (Uniprobe, Cardiff) ensured oxygen sufficiency. The $\mathrm{pH}$ was controlled at 6.5 using automatic addition of $5 \mathrm{M}-\mathrm{NAOH}$.

The fermenter was inoculated with a suspension of filamentous mycelia $(50 \mathrm{ml})$ grown from a spore inoculum in a magnetically stirred flask culture. Flask and fermenter culture media contained $\left(\mathrm{g} \mathrm{l}^{-1}\right)$ : glucose, 22; $\mathrm{Na}_{2} \mathrm{HPO}_{4}$, $3.77 ; \mathrm{KH}_{2} \mathrm{PO}_{4}, 10.5 ; \mathrm{NH}_{4} \mathrm{Cl}, 5.0 ;$ EDTA $\mathrm{Na}_{2} .2 \mathrm{H}_{2} \mathrm{O}, 0.6 ; \mathrm{NaOH}, 0.1 ; \mathrm{MgSO}_{4} .7 \mathrm{H}_{2} \mathrm{O}, 0.25 ; \mathrm{CaCl}_{2}, 0.05 ;$ $\mathrm{ZnSO}_{4} .7 \mathrm{H}_{2} \mathrm{O}, 0.02 ; \mathrm{MnSO}_{4} .4 \mathrm{H}_{2} \mathrm{O}, 0.02 ; \mathrm{CuSO}_{4} .5 \mathrm{H}_{2} \mathrm{O}, 0.005 ; \mathrm{FeSO}_{4} .7 \mathrm{H}_{2} \mathrm{O}, 0.1 ; \mathrm{Na}_{2} \mathrm{SO}_{4}, 0.5 ; \mathrm{Na}_{2}-$ $\mathrm{MoO}_{4} .2 \mathrm{H}_{2} \mathrm{O}, 0.005 ; \mathrm{CoCl}_{2} .6 \mathrm{H}_{2} \mathrm{O}, 0.05 ; \mathrm{Na}_{2} \mathrm{~B}_{4} \mathrm{O}_{7} .10 \mathrm{H}_{2} \mathrm{O}, 0.005$. Glucose, phosphates and the other constituents were sterilized separately as distilled water solutions. The mineral salts solution used to reverse the cyclopentenedione activity was a $\times 10$ concentrate of the medium with glucose, $\mathrm{NH}_{4} \mathrm{Cl}$ and phosphates omitted. One $\mathrm{ml}$ solution was added to $2 \mathrm{ml}$ sample and the results compared with a control with distilled water added. Rapid culture sampling on to sintered glass filters (porosity 3) under vacuum was used to prepare samples for analysis. Replicate batch culture runs were obtained by running fresh medium into the fermenter using $50 \mathrm{ml}$ from the previous culture as inoculum. The analyses reported here were obtained from cultures inoculated in this way.

Analytical procedures. Samples for dry weight determination were pipetted into tared glass tubes and centrifuged at $2000 \mathrm{~g}$ for $15 \mathrm{~min}$. The pellet was washed with distilled water and dried to a constant weight at $105^{\circ} \mathrm{C}$. Analysis of the dried effluent gas stream was accomplished using a paramagnetic oxygen analyser (model OA 540, Servomex, Crowborough, Sussex) and an infra-red $\mathrm{CO}_{2}$ analyser (model IRGA 20, Grubb Parsons, Newcastle on Tyne). Airflow was monitored throughout the system. The gases were analysed continuously on-line and the values were recorded on a chart recorder. Calculated data, such as R.Q. values were computed at hourly intervals.

Glucose was estimated using a phenol/sulphuric acid method (Herbert et al., 1971). Ammonia concentration was determined by the indophenol blue method of Allen et al. (1974). Phosphate was determined by the method of Mackereth et al. (1978).

Mycelial RNA was extracted with $30 \%(\mathrm{v} / \mathrm{v}) \mathrm{HClO}_{4}$ and assayed by the orcinol procedure of Herbert et al. (1971). Protein was determined using the biuret method (bovine serum albumin standard) of Herbert et al. (1971). These assays were performed on fresh samples to avoid degradation during storage.

Cobalt was determined using the nitroso-R salt method of Marczenco (1976).

Samples of mycelium for microanalysis were freeze-dried and ground to a finely divided powder which was then dried overnight in vacuo over $\mathrm{P}_{2} \mathrm{O}_{5}$. Carbon, hydrogen and nitrogen were determined by flash combustion, and oxygen by pyrolysis. All determinations were carried out using a Carlo Erba Elemental Analyser, model 1106 (Milan, Italy). Samples for microanalysis of culture supernatant were evaporated to dryness in vacuo at $50^{\circ} \mathrm{C}$.

Melanin was estimated using the method of Bull (1970). Synthetic melanin (Sigma) prepared by persulphate oxidation of tyrosine was used as a standard. Elemental analysis revealed a similar empirical formula to that of the brown crystals resulting from Bull's procedure.

Antibiotic assays. Fresh culture supernatants were assayed for antibiotic activity by cup-plate bioassay with Staphylococcus aureus Oxford H strain VI and Comamonas terrigena ATCC 8461 using pure samples of thienamycin, cephamycin C (Merck, Sharp and Dohme, N.J., U.S.A.) and penicillin N (Glaxo) as standards. Qualitative estimation of antimicrobial products was performed using the thin-layer chromatographic methods of Lilley $e t$ al. (1981) and Noble et al. (1978). Quantification was made from cup-plate inhibition zone sites based on the following rationale: cyclopentenedione activity on $S$. aureus was reversed by mineral salts solution $(\mathrm{a} \times 10$ concentrate of the fermenter medium with glucose, $\mathrm{NH}_{4} \mathrm{Cl}$ and phosphates omitted); cephamycin $\mathrm{C}$ was active against $S$. aureus only and was not reversed by mineral salts; and thienamycin was active against $C$. terrigena only. Thus at concentrations obtained during fermentation discrimination between the products was possible.

Sampling. Experimental data were obtained at $6 \mathrm{~h}$ intervals except where turning points were evident, in which case 2-h samples were taken. The length of the lag phase varied between runs but the lengths of the subsequent 


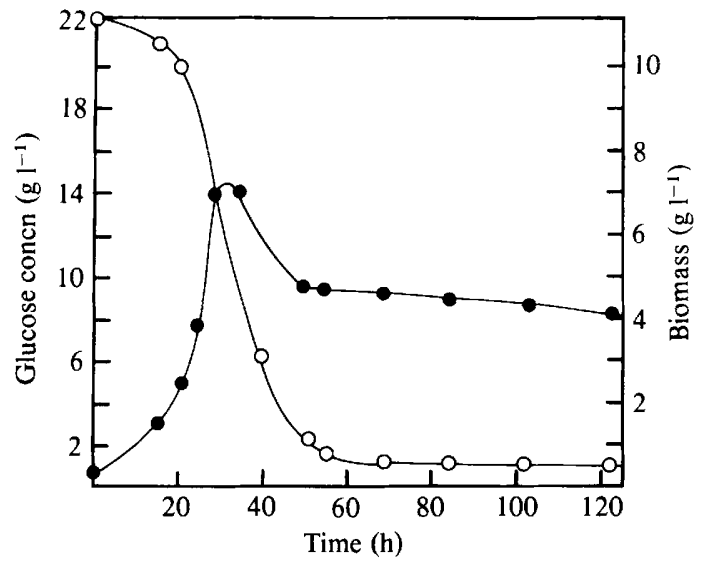

Fig. 1.

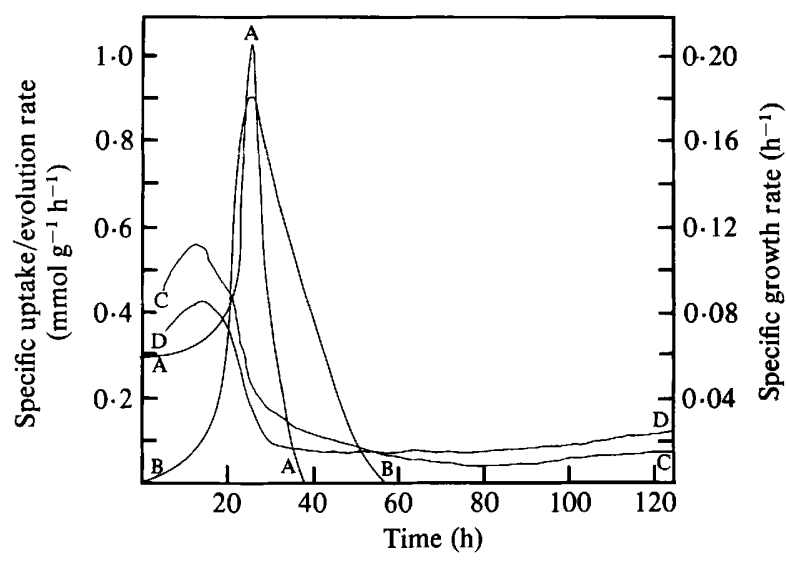

Fig. 2.

Fig. 1. Observed concentrations of biomass (O) and glucose $(O)$ during batch culture of $S$. cattleya.

Fig. 2. Specific growth rate and nutrient/metabolite exchange rates during the $S$. cattleya batch culture, calculated from cubic spline fits to the observed data (see Computer methods): $\mathrm{A}, \mu ; \mathrm{B}, q_{\mathrm{glucose}} ; \mathrm{C}, q_{\mathrm{O}_{2}}$; $\mathrm{D}, q_{\mathrm{CO}_{2}}$

phases were consistent at the $90 \%$ confidence level over five successive cultures, using R.Q. as an indicator of phase length. All analytical results presented here were taken from a single run which exhibited a typical R.Q. profile.

Computer methods. All the two-dimensional curves presented were plotted using cubic spline fits (Ahlberg et al., 1967). This method provides a curve which passes through all the data points so that, unlike a regression procedure, a quotient indicating accuracy of fit is not calculated. Where specific growth, nutrient uptake and metabolite production rates were presented (Figs 2 and 6) cubic splines were calculated for volumetric concentration data using an algorithm which also returns gradient values at data points and intermediate values. The gradient values were then used to calculate the quotient values in Figs 2 and 6.

The isometric projection in Fig. 8 was plotted using the Gino F package (version 2.1, Computer Aided Design Centre, Madingley Road, Cambridge).

All programs were written in Fortran IV by M. E. Bushell and run on the University of Surrey Prime computer system (Prime Computer Inc., Framingham, Mass., U.S.A.).

\section{RESULTS AND DISCUSSION}

\section{Sequence of events in batch culture}

Culture biomass concentration peaked at $33 \mathrm{~h}\left(7 \cdot 1 \mathrm{~g} \mathrm{l}^{-1}\right)$ decreasing rapidly thereafter until $50 \mathrm{~h}$. From this point, a slower rate of biomass loss accompanied product formation (Fig. 1).

Maximum respiratory activity (Fig. 2) as measured by specific oxygen uptake and carbon dioxide evolution rates $\left(q_{\mathrm{O}_{2}}\right.$ and $q_{\mathrm{CO}_{2}}$ respectively) coincided with maximum phosphate uptake $\left(q_{\mathrm{PO}_{4}}\right)$ (Fig. 6). This period preceded the attainment of maximum specific growth $(\mu)$ and glucose uptake $\left(q_{\text {glucose }}\right)$ rates (Fig. 2). The R.Q., however, remained between 0.79 and 0.83 throughout the biomass accretion phase (Fig. 3). Thereafter, it increased in a stepwise manner at $35 \mathrm{~h}, 55 \mathrm{~h}$, $70 \mathrm{~h}$, and $105 \mathrm{~h}$, eventually attaining a value of 1.97 at $125 \mathrm{~h}$. The first increase coincided with lysis. Each of the subsequent increases coincided with the first detection of a new product in the culture supernatant.

The first extracellular metabolite detected was the cyclopentenedione compound (Fig. 4) described by Noble et al. (1978) as 2-hydroxy-2-hydroxymethylcyclopent-4-ene-1,3-dione. Biosynthesis took place between $50 \mathrm{~h}$ and $55 \mathrm{~h}$ (Fig. 5), after which the concentration of the compound in the culture began to decrease. Melanin production was then observed between $55 \mathrm{~h}$ and $73 \mathrm{~h}$ (Fig. 5) and the compound again appeared to break down after the biosynthetic peak. Cephamycin $\mathrm{C}$ was produced between $70 \mathrm{~h}$ and $115 \mathrm{~h}$ and thienamycin production started at $115 \mathrm{~h}$ (Fig. 5). 


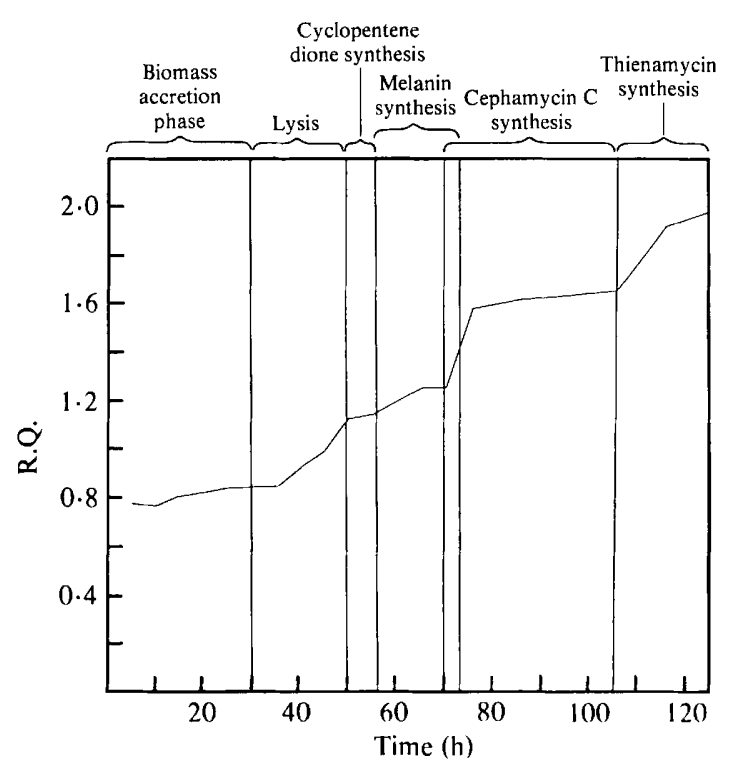

Fig. 3. Respiratory quotient (R.Q.) and different physiological phases during the $S$. cattleya batch culture.<smiles>O=C1C=CC(=O)C1(O)CO</smiles>

Fig. 4. The cyclopentenedione compound (2-hydroxy-2-hydroxymethylcyclopent-4-ene-1,3-dione). Structure according to Noble et al. (1978).

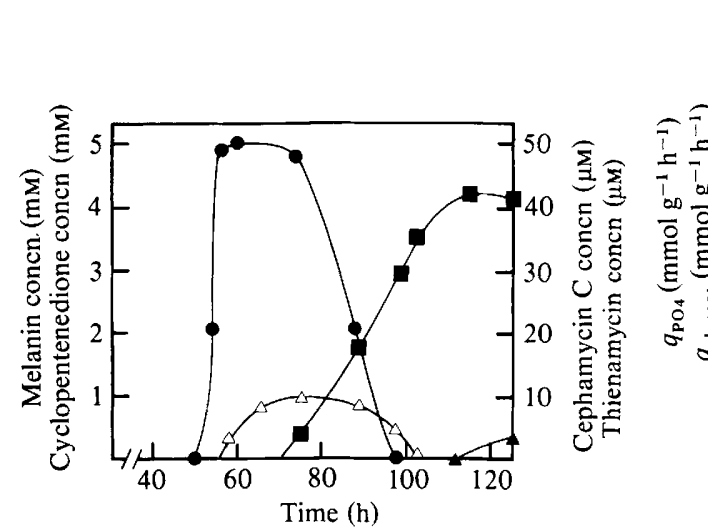

Fig. 5 .

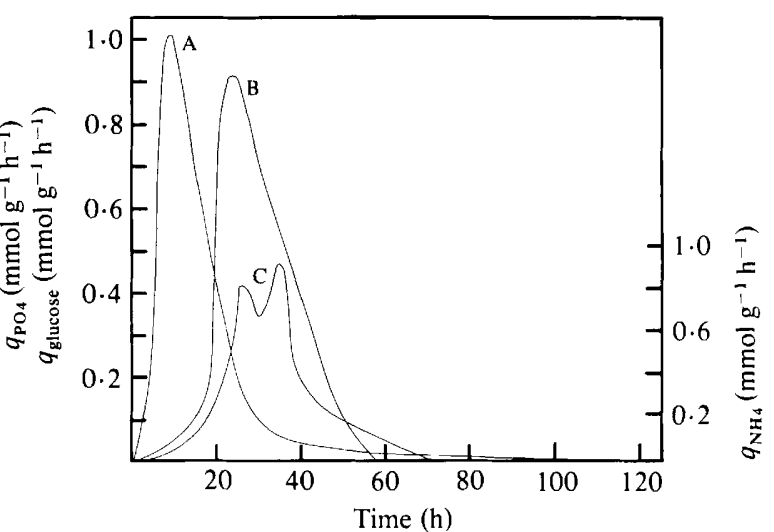

Fig. 6.

Fig. 5. Extracellular product formation in the $S$. cattleya batch culture. Cyclopentenedione; $\triangle$, melanin; $\boldsymbol{\square}$, cephamycin $\mathrm{C} ; \boldsymbol{\Delta}$, thienamycin.

Fig. 6. Specific nutrient uptake rates in $S$. cattleya batch culture, calculated from cubic spline fits to the observed data (see Computer methods). A, $q_{\mathrm{PO}_{4}} ; \mathrm{B}, q_{\mathrm{glucose}} ; \mathrm{C}, q_{\mathrm{NH}_{4}}$. 
Secondary metabolite production in S. cattleya

Table 1. Effect of pulse addition of nutrients to the culture

\begin{tabular}{|c|c|c|c|c|c|c|}
\hline \multirow[b]{2}{*}{ Time (h) } & \multicolumn{3}{|c|}{$\begin{array}{l}\text { Specific nutrient uptake } \\
\left(\mathrm{mmol} \mathrm{g}^{-1} \mathrm{~h}^{-1}\right)\end{array}$} & \multicolumn{3}{|c|}{ Effect of nutrient addition*: } \\
\hline & $\widetilde{q_{\text {glucose }}}$ & $q_{\mathrm{NH}_{4}}$ & $\overbrace{q_{\mathrm{PO}_{4}}}$ & Glucose & Glucose $+\mathrm{NH}_{4} \mathrm{Cl}$ & $\begin{array}{l}\text { Glucose }+\mathrm{NH}_{4} \mathrm{Cl} \\
+ \text { phosphates }\end{array}$ \\
\hline 10 & 0.05 & $0 \cdot 11$ & 1.04 & - & - & - \\
\hline 20 & 0.82 & $0 \cdot 30$ & 0.41 & - & - & - \\
\hline 30 & 0.71 & $0 \cdot 61$ & 0.90 & - & - & - \\
\hline 40 & 0.43 & $0 \cdot 30$ & $0 \cdot 50$ & - & - & - \\
\hline 50 & $0 \cdot 10$ & 0.18 & $0 \cdot 30$ & - & - & - \\
\hline 60 & 0 & 0.01 & $0 \cdot 20$ & + & + & + \\
\hline 70 & 0 & 0 & $0 \cdot 15$ & - & + & + \\
\hline 80 & 0 & 0 & $0 \cdot 10$ & - & + & + \\
\hline 90 & 0 & 0 & $0-0 \cdot 10$ & - & + & + \\
\hline 100 & 0 & 0 & $0-0 \cdot 10$ & - & + & + \\
\hline 110 & 0 & 0 & $0-0 \cdot 10$ & - & + & + \\
\hline 120 & 0 & 0 & 0 & - & - & + \\
\hline
\end{tabular}

* $10 \mathrm{ml}$ quantities were added to the cultures. Glucose concentration was $1.5 \mathrm{M}$, ammonium chloride and $\mathrm{Na}_{2} \mathrm{HPO}_{4} / \mathrm{KH}_{2} \mathrm{PO}_{4}$ solutions were $1.0 \mathrm{M}$. + indicates biomass increase; - indicates no effect on biomass.

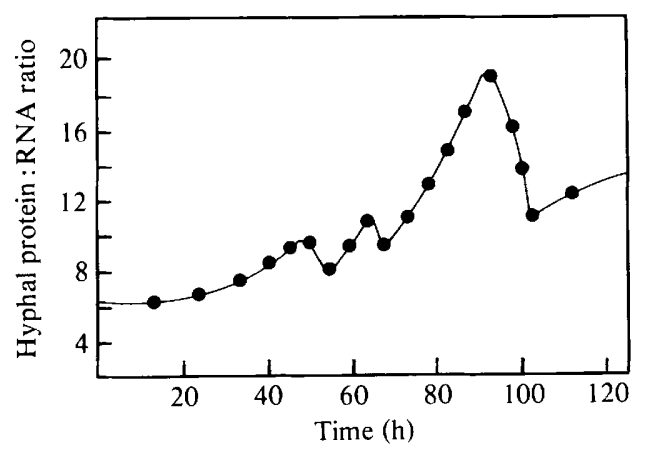

Fig. 7. Protein : RNA ratio in $S$. cattleya batch culture.

Glucose was the first nutrient to become limiting (Fig. 6). Maximum detectable ammonium uptake took place between $30 \mathrm{~h}$ and $40 \mathrm{~h}$ and $q_{\mathrm{NH}_{4}}$ (specific ammonium assimilation rate) reached zero at $70 \mathrm{~h} . q_{\mathrm{PO}_{4}}$ peaked at $10 \mathrm{~h}$ and finally approached zero at $115 \mathrm{~h}$. The decay to zero of $q_{\text {glucose }}, q_{\mathrm{NH}_{4}}$ and $q_{\mathrm{PO}_{4}}$ coincided with the initiation of, respectively, melanin, cephamycin C and thienamycin production (Figs 5 and 6). On attainment of minimum $q$ value, the addition of the appropriate nutrient or nutrients to the culture resulted in an immediate biomass increase, indicating a growth potential which was nutrient limited at that point (Table 1).

No penicillin $\mathrm{N}$ or $\mathrm{N}$-acetylthienamycin were detected. As a probable precursor to cephamycin C (Sawada et al., 1979), penicillin $\mathrm{N}$ may have been formed transiently or in low concentrations.

\section{Macromolecular composition}

The ratio of hyphal protein to hyphal RNA content peaked at $50 \mathrm{~h}, 65 \mathrm{~h}$ and $90 \mathrm{~h}$ (Fig. 7). It was not possible to calculate the 'ribosomal efficiency' quantity proposed by Alroy \& Tannenbaum (1973) as the progressive fall in biomass concentration during the productive phase of the culture resulted in negative specific growth rate values. The ratio increased after each $q$ value approached zero. A maximum was observed during each different nutrient limitation phase. These results are consistent with findings of Pitt \& Bull (1982) who have suggested that ribosomal efficiency in Trichoderma aureoviridie is controlled by the nature and availability of growth-limiting concentrations of ammonia and glucose. 
Table 2. Reported biomass composition

\begin{tabular}{|c|c|c|c|c|c|}
\hline Organism & Formula & Reductance & R.Q. for glucose & Yield & Reference \\
\hline Brevibacterium spp. & $\mathrm{CH}_{1.625} \mathrm{O}_{0.5} \mathrm{~N}_{0.125}$ & $4 \cdot 25$ & NA & NA & Erickson et al. (1979) \\
\hline $\begin{array}{l}\text { Saccharomyces } \\
\text { cerevisiae }\end{array}$ & $\mathrm{CH}_{1.7} \mathrm{O}_{0.5} \mathrm{~N}_{0.17}$ & $4 \cdot 19$ & $1 \cdot 04$ & 0.5 & $\begin{array}{l}\text { Cooney et al. (1977); } \\
\text { Wang et al. (1977) }\end{array}$ \\
\hline Candida utilis & $\mathrm{CH}_{1.84} \mathrm{O}_{0.56} \mathrm{~N}_{0.2}$ & $4 \cdot 12$ & $1 \cdot 16$ & 0.54 & Herbert (1976) \\
\hline 'Most micro-organisms' & $\mathrm{CH}_{1.65} \mathrm{O}_{0.525} \mathrm{~N}_{0.2}$ & $4 \cdot 00$ & NA & NA & Roels (1980) \\
\hline S. cattleya & $\mathrm{CH}_{1.6} \mathrm{O}_{0.58} \mathrm{~N}_{0.17}$ & 3.93 & 0.8 & 0.78 & Present study \\
\hline
\end{tabular}

\section{Elemental composition of biomass and culture supernatant}

Results of $\mathrm{C}, \mathrm{H}, \mathrm{N}$ and $\mathrm{O}$ analyses of dried mycelium varied between samples taken throughout the culture. When the standard error of the mean was determined, however, the variation was found to be insignificant at $95 \%$ confidence limits and the mean value obtained for each element was used to determine the composition of biomass. The values $\mathrm{C}(47.5 \%)$, $\mathrm{H}(6.3 \%), \mathrm{O}(36.7 \%), \mathrm{N}(9.4 \%)$ give an empirical formula of $\mathrm{CH}_{1.6} \mathrm{O}_{0.58} \mathrm{~N}_{0.17}$. A mole of biomass, therefore, contains $25 \cdot 26 \mathrm{~g}$.

\section{Biomass accretion phase}

The fermentation mass balance (equation 1) was calculated for the period $5 \mathrm{~h}$ to $30 \mathrm{~h}$, adopting the rationale of Herbert (1976). The multiphasic nature of this period (Figs 2 and 5) suggests that resolution of the mass balance over shorter time intervals could have been more revealing, but the lack of significant variability in the elemental analysis and the accuracy limits of the assays for the components concerned precluded this approach. No extracellular metabolites or lytic products were detected and good agreement was obtained between carbon substrate consumed and products formed. An accurate Monod yield factor (weight of biomass formed per unit weight of substrate consumed) may, therefore, be obtained from the balance.

$$
0.19 \mathrm{C}_{6} \mathrm{H}_{12} \mathrm{O}_{6}+0.17 \mathrm{NH}_{3}+0.094 \mathrm{O}_{2} \rightarrow \underset{\text { Biomass }}{\mathrm{CH}_{1.6} \mathrm{O}_{0.58} \mathrm{~N}_{0.17}}+0.077 \mathrm{CO}_{2}+0.6 \mathrm{H}_{2} \mathrm{O}
$$

The value (0.73) is surprisingly high, but is consistent with the oxidized nature of the biomass. The reductance degree (gamma) of a mass balance component was defined by Erickson et al. (1979) as the number of available electrons in one g-atom based on carbon $=4$, hydrogen $=1$, oxygen $=-2$ and nitrogen (in biomass and ammonia) $=-3$.

The reductance degree of $S$. cattleya biomass is therefore:

$$
4+(1.6)+(0.58 \times-2)+(0.17 \times-3)=3.93
$$

Values in the range 4 to 4.25 may be calculated for biomass analyses reported in other microorganisms (Table 2). Equivalent values for R.Q. and yield are sparse but are usually greater than 1 (R.Q.) and less than 0.7 (yield). The theoretical interdependence of R.Q., yield and gamma is shown in Fig. 8. Similar values of gamma obtained from different biomass compositions show the same trends. R.Q. decreases as yield is increased at low gamma values, whereas R.Q. increases with gamma at high yield values. For high values of gamma, less variation of R.Q. with yield is evident.

\section{Lysis}

The first significant increase in R.Q. occurred at $35 \mathrm{~h}$ when lysis was observed microscopically and the value rose progressively. Extracellular product (equation 2) was observed in the culture supernatant and large quantities of foam were produced in the fermenter. Foaming in synthetic media is usually associated with cell lysis (Bryant, 1970). It is likely that the 'extracellular product' corresponding to $\mathrm{CH}_{1.6} \mathrm{O}_{0.58} \mathrm{~N}_{0.17}$ (equation 2) is composed of the supernatant of lysed hyphae. This observation provided a means for more effective foam control 


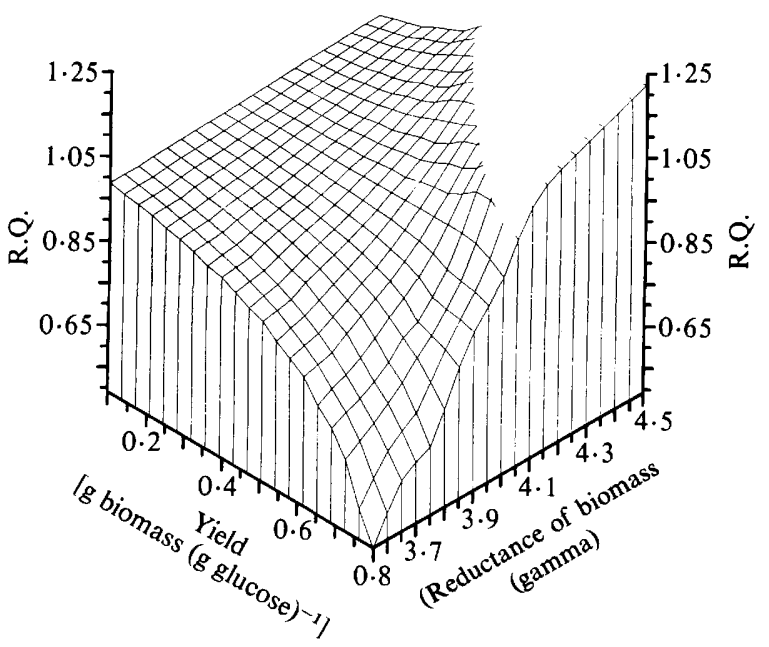

Fig. 8. Theoretical interdependence of R.Q., yield and reductance degree calculated from the stoichiometry of biomass, $\mathrm{CO}_{2}$ and water formation from glucose, oxygen and ammonia for R.Q. values in the range 0.5 to 1.25 , reductance values in the range 3.6 to 4.5 , and yield factors [ $\mathrm{g}$ biomass ( $\mathrm{g}$ glucose $\left.^{-1}\right)$ ] in the range 0.1 to $0 \cdot 8$. Co-ordinates in the blank area of the surface are outside the physically-possible range, requiring $100 \%$ or greater conversion of substrate carbon to biomass. The model assumes biomass compositions within the range $\mathrm{CH}_{1.5} \mathrm{O}_{0.4} \mathrm{~N}_{0.15}$ to $\mathrm{CH}_{1.9} \mathrm{O}_{0.6} \mathrm{~N}_{0.25}$.

in subsequent experiments as the rate of antifoam addition could be automatically increased as a response to the characteristic rise in R.Q. The mean R.Q. value obtained during this period may be explained by reference to equation 2 . Overall, glucose, ammonia, oxygen and biomass were converted to carbon dioxide and extracellular product.

$$
\underset{\text { Biomass }}{\mathrm{CH}_{1.6} \mathrm{O}_{0.58} \mathrm{~N}_{0.17}}+\underset{0.69 \mathrm{C}_{6} \mathrm{H}_{12} \mathrm{O}_{6}}{+0.14 \mathrm{O}_{2}}+\underset{\text { Lysis products? }}{0.23 \mathrm{NH}_{3}} \rightarrow \underset{\text { ? }}{0.44 \mathrm{CH}_{1.1} \mathrm{ON}_{0.08}}+0.12 \mathrm{CO}_{2}+0.22 \mathrm{H}_{2} \mathrm{O}
$$

\section{Product formation}

Synthesis of the cyclopentenedione compound took place over the period 50-55 h. No net change in biomass concentration took place, although extracellular product which could have resulted from lysis was detected. The interpretation would be that lysis and growth were balanced. One mol cyclopentenedione was apparently formed per 1.23 mol glucose consumed (equation 3).

$$
\begin{aligned}
& 1 \cdot 23 \mathrm{C}_{6} \mathrm{H}_{12} \mathrm{O}_{6}+0 \cdot 18 \mathrm{NH}_{3}+0.32 \mathrm{O}_{2} \rightarrow \mathrm{C}_{6} \mathrm{H}_{6} \mathrm{O}_{4}+0.36 \mathrm{CO}_{2}+0.98 \mathrm{CH}_{2 \cdot 5} \mathrm{O}_{0 \cdot 19} \mathrm{~N}_{0 \cdot 18}+3 \cdot 1 \mathrm{H}_{2} \mathrm{O} \\
& \text { Cyclo- Lysis? } \\
& \text { pentene- } \\
& \text { dione }
\end{aligned}
$$

The initiation of melanin formation coincided with the end of lysis (as shown by microscopy, elemental analysis of culture supernatant and lack of foaming). The implication that melanin is an inhibitor of lysis (Bull, 1970) is consistent with this observation. The detection of melanin is at variance with the original description of the species (Kahan et al., 1979). A mass balance (equation 4) was derived from the product yield, $q_{\mathrm{CO}_{2}}$ and $q_{\mathrm{O}_{2}}$ values observed, which could account for the changes seen in biomass and ammonia concentrations. The increase in R.Q. when melanin biosynthesis started is, therefore, taken as an indicator of the resultant change in stoichiometry.

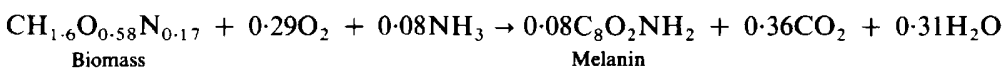

Similar changes were observed as each new product was synthesized. The appropriate mass balances are shown in equations 5 and 6 . Biomass consumption figures in equations 4 and 6 were 


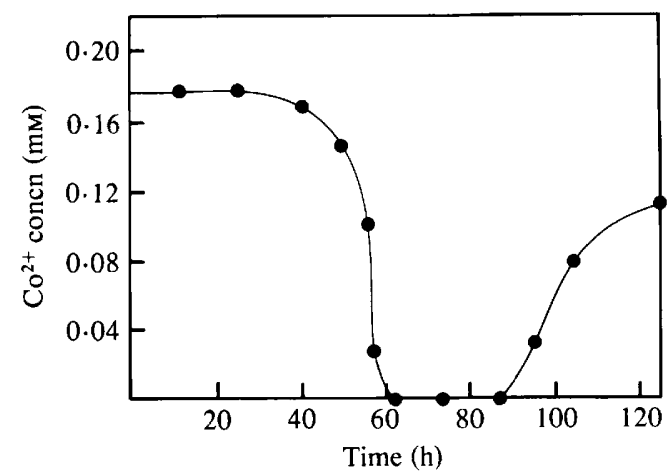

Fig. 9. Apparent free cobalt assayed by the nitroso-R salt method (Marczenco, 1976) in the $S$. cattleya batch culture supernatant.

calculated from the carbon balance as the small differences obtained were beyond the resolution limits for accurate dry weight determination.

$$
\begin{aligned}
& \mathrm{CH}_{1.6} \mathrm{O}_{0.58} \mathrm{~N}_{0.17}+0.37 \mathrm{O}_{2} \rightarrow 0.001 \mathrm{C}_{8} \mathrm{O}_{2} \mathrm{NH}_{2}+0.02 \mathrm{C}_{19} \mathrm{~N}_{4} \mathrm{H}_{23} \mathrm{O}_{9} \mathrm{~S}+0.08 \mathrm{NH}_{3}+0.62 \mathrm{CO}_{2}+0 \cdot 15 \mathrm{H}_{2} \mathrm{O} \\
& \text { Cephamycin } \mathrm{C} \\
& 1.83 \times 10^{-3} \mathrm{O}_{2}+4.065 \times 10^{-3} \mathrm{CH}_{1.6} \mathrm{O}_{0.58} \mathrm{~N}_{0.17} \rightarrow 3.611 \times 10^{-3} \mathrm{CO}_{2}+3.674 \times 10^{-5} \mathrm{C}_{11} \mathrm{H}_{16} \mathrm{~N}_{2} \mathrm{O}_{4} \mathrm{~S}
\end{aligned}
$$

\section{Cobalt concentration}

The bacteriostatic effect of the cyclopentenedione could be overcome by supplementing the challenge culture medium with mineral salts solution (see Methods). This is similar to the effect observed with the hydroxamic acids (Neilands, 1967) and other antibiotics whose activity involves the sequestration of metal ions (Zahner, 1978).

The concentration of free cobalt ions, detected by the spectrophotometric assay, decreased to zero at $55 \mathrm{~h}$ (Fig. 9), coinciding with maximum production of cyclopentenedione. This suggests that the compound is a chelating agent for cobalt under these conditions. Subsequent samples then exhibited a progressive increase in free cobalt, coincident with a decay in cyclopentenedione concentration.

\section{Effect of phosphate on thienamycin stability}

The changes in product detected with each successive nutrient limitation are consistent with the observations of Lilley et al. (1981) whose chemostat experiments led them to conclude that thienamycin and cephamycin $C$ were, respectively, regulated by phosphate and ammonium uptake. The increased instability of thienamycin in the presence of phosphate (Kahan et al., 1979), however, complicated the interpretation of these and our own results. Lack of detectable thienamycin in the presence of culture phosphate may simply indicate product breakdown. Our observations of the stepwise alteration in R.Q. is, however, circumstantial evidence that thienamycin is only synthesized during the phase of phosphate limitation.

We are grateful to Merck, Sharp and Dohme, Rahway, N.J., U.S.A. for the gift of pure samples of antibiotics; to Mr D. Noble (Glaxo Group Research Ltd, Greenford, Middlesex) for data for the quantification of the cyclopentenedione and to Mr D. Boyles (B. P., Sunbury, Kent) for many helpful discussions.

\section{REFERENCES}

Aharonowitz, Y. \& Demain, A. L. (1977). Influence of inorganic phosphate and organic buffers on cephalosporin production by Streptomyces clavuligerus. Archives of Microbiology 115, 169-173.
Aharonwitz, Y. \& Demain, A. L. (1978). Carbon catabolite regulation of cephalosporin production in Streptomyces clavuligerus. Antimicrobial Agents and Chemotherapy 14, 159-164. 
Aharonowitz, Y. \& Demain, A. L. (1979). Nitrogen nutrition and regulation of cephalosporin production in Streptomyces clavuligerus. Canadian Journal of Microbiology 25, 61-67.

AhlberG, J. H., Nilson, E. N. \& Walsh, J. L. (1967). The Theory of Splines and Their Application. London: Academic Press.

Allen, S. E., Grimshaw, H. M., Parkinson, J. A. \& QUARMBY, C. (1974). Chemical Analyses of Ecological Materials. Oxford: Blackwell Scientific Publications.

Alroy, Y. \& Tannenbaum, S. R. (1973). The influence of environmental conditions on the macromolecular composition of Candida utilis. Biotechnology and Bioengineering 15, 239-256.

BRYANT, J. (1970). Antifoam agents. Methods in Microbiology 2, 187-203.

BulL, A. T. (1970). Inhibition of polysaccharases by melanin: enzyme inhibition in relation to mycolysis. Archives of Biochemistry and Biophysics 137, 345356.

Bushell, M. E. (1982). Microbiological aspects of the discovery of novel secondary metabolites. In Topics in Enzyme and Fermentation Biotechnology 6, pp. 3267. Edited by A. Wiseman. Chichester: Ellis Horwood.

Bushell, M. E. \& NisBet, L. J. (1981). A technique for eliminating recurring producers of known metabolites in antibiotic screens. Zentralblatt für Bakteriologie, Mikrobiologie und Hygiene. Supplement 11 , 507-514.

CoONEY, C. L., WANG, H. Y. \& WANG, D. I. C. (1977). Computer aided material balancing for prediction of fermentation parameters. Biotechnology and Bioengineering 19, 55-67.

Erickson, L. E., Minkewich, I. G. \& Eroshin, V. K. (1979). Utilization of mass-energy balance regularities in the analysis of continuous culture data. Biotechnology and Bioengineering 21, 575-591.

HerberT, D. (1976). Stoicheiometric aspects of microbial growth. In Continuous Culture 6: Applications and New Fields, pp. 1-39. Edited by A. C. R. Dean, D. C. Ellwood, C. G. T. Evans \& J. Melling. Chichester: Ellis Horwood.

Herbert, D., Phipps, P. J. \& Strange, R. E. (1971). Chemical analysis of microbial cells. Methods in Microbiology 5B, 209-344.

Hopwood, D. A. (1981). Genetic studies of antibiotic and other secondary metabolites. In Genetics as a Tool in Microbiology pp. 187-218. Edited by S. W. Glover \& D. A. Hopwood. Cambridge: Cambridge University Press.

Kahan, J. S., Kahan, F. M., Goegelman, R., Curris, S. A., Jackson, M., Stapley, E. O. Miller, T. W.,
Miller, A. K., Hendlin, D., Mochales, S., Hernandez, S., Woodruff, H. B. \& Birnbaum, J. (1979). Thienamycin, a new beta-lactam antibiotic. I. Discovery, taxonomy, isolation and physical properties. Journal of Antibiotics 32, 1-12.

Kitano, K., Kintaka, K., Suzuki, S., Katamoto, K., Nara, K., \& NaKaO, Y. (1975). Production of betalactam antibiotics. I. Screening of microorganisms capable of producing beta-lactam antibiotics. Hakko Kogaku Zasshi 53, 327-338.

Lilley, G., Clark, A. E. \& Lawrence, G. C. (1981). Control of the production of cephamycin $\mathrm{C}$ and thienamycin by Streptomyces cattleya NRRL 8057. Journal of Chemical Technology and Biotechnology 31, 127-134.

Mackereth, F. J. H., Heron, J. \& Talling, J. F. (1978). Water Analysis. Freshwater Biological Association Scientific Publication no. 36.

MARCZENCO, C. (1976). Spectrophotometric Determination of Elements. Chichester: Ellis Horwood.

Martin, J. F. \& Demain, A. L. (1980). Control of antibiotic synthesis. Microbiological Reviews 44, 230251.

Napier, E. J., Evans, J. R., Noble, D., Bushell, M. E., WebB, G. \& Brown, D. (1977). Chemical compounds (metabolites of Streptomyces clavulgerus). German Patent 2725690.

NeILANDS, J. B. (1967). Hydroxamic acids in nature. Science 156, 1443-1447.

Noble, M., Noble, D.\& Fleton, R. A. (1978). G2201$C$, A new cyclopentenedione antibiotic isolated from the fermentation broth of Streptomyces cattleya. Journal of Antibiotics 31, 15-18.

PITT, D. E. \& BulL, A. T. (1982). Influence of culture conditions on the physiology and composition of Trichoderma aureoviride. Journal of General Microbiology 128, 1517-1527.

ROELS, J. A. (1980). Simple model for the energetics of growth on substrates with different degrees of reduction. Biotechnology and Bioengineering 22, 3353.

Sawada, Y., Hunt, N. A. \& Demain, A. L. (1979). Further studies on microbiological ring expansion of penicillin N. Journal of Antibiotics 32, 1303-1310.

UMEZAWA, H. (1967). Index of Antibiotics from Actinomycetes. Tokyo: University of Tokyo Press.

WANG, H. Y., COONEY, C. L. \& WANG, D. I. C. (1977). Computer aided baker's yeast fermentations. Biotechnology and Bioengineering 19, 69-86.

ZAHNER, H. (1978). The search for new secondary metabolites. In Antibiotics and Other Secondary Metabolites, pp. 1-17. Edited by R. Hutter, T. L. Leisimaer, J. Nuesch \& W. Wehrli. London: Academic Press. 